\title{
Mastering the Core Competencies of Electrical Engineering through Knowl- edge Integration
}

\section{Prof. Tom Chen, Colorado State University}

Tom Chen received his Ph.D. from the University of Edinburgh. After spending 4 years with Philips Semiconductors in Europe, he joined the Department of Electrical \& Computer Engineering at Colorado State University. Prof. Chen published more than 180 journal and conference papers in the areas of analog and digital VLSI design and CAD for VLSI design. Prof. Chen served as General Chair of 2015 IEEE Midwest Symposium on Circuits and Systems, and as the Guest Editor of the IEEE Trans. on ComputerAided Design of Integrated Circuits and Systems special issue on Design Quality and Design Closure: Present Issues and Future Trend", 2005. He also served as the Guest Editor of the Microelectronics Journal on Quality Electronic Design, 2005. His research interests include VLSI circuit and system design, CAD methodology for VLSI design, and bioelectronics.

Prof. Anthony A. Maciejewski, Colorado State University

Anthony A. Maciejewski received the BSEE, MS, and PhD degrees from the Ohio State University in 1982, 1984, and 1987, respectively.From 1988 to 2001, he was a professor of electrical and computer engineering at Purdue University, West Lafayette. He is currently a professor and the department head of Electrical and Computer Engineering at Colorado State University. He is a fellow of the IEEE. A complete vita is available at: http://www.engr.colostate.edu/ aam.

\section{Prof. Branislav M. Notaros, Colorado State University}

Branislav M. Notaros is Professor in the Department of Electrical and Computer Engineering at Colorado State University, where he also is Director of Electromagnetics Laboratory. He received a Ph.D. in electrical engineering from the University of Belgrade, Yugoslavia, in 1995. His research publications in computational and applied electromagnetics include more than 150 journal and conference papers. He is the author of textbooks Electromagnetics (2010) and MATLAB-Based Electromagnetics (2013), both with Pearson Prentice Hall. Prof. Notaros served as General Chair of FEM2012, Colorado, USA, and as Guest Editor of the Special Issue on Finite Elements for Microwave Engineering, in Electromagnetics, 2014. He was the recipient of the 1999 Institution of Electrical Engineers (IEE) Marconi Premium, 2005 Institute of Electrical and Electronics Engineers (IEEE) MTT-S Microwave Prize, 2005 UMass Dartmouth Scholar of the Year Award, 2012 Colorado State University System Board of Governors Excellence in Undergraduate Teaching Award, 2012 IEEE Region 5 Outstanding Engineering Educator Award, 2014 Carnegie Foundation for the Advancement of Teaching Colorado Professor of the Year Award, 2015 American Society for Engineering Education ECE Distinguished Educator Award, 2015 IEEE Undergraduate Teaching Award, and many other research and teaching awards.

\section{Prof. Ali Pezeshki, Colorado State University}

Ali Pezeshki received the BSc and MSc degrees in electrical engineering from University of Tehran, Tehran, Iran, in 1999 and 2001, respectively. He earned his PhD degree in electrical engineering at Colorado State University in 2004. In 2005, he was a postdoctoral research associate with the Electrical and Computer Engineering Department at Colorado State University. From January 2006 to August 2008, he was a postdoctoral research associate with The Program in Applied and Computational Mathematics at Princeton University. In August 2008, he joined the faculty of Colorado State University, where he is now an Associate Professor in the Department of Electrical and Computer Engineering, and the Department of Mathematics. His research interests are in statistical signal processing, coding theory, applied harmonic analysis, and bioimaging.

\section{Ms. Melissa D. Reese, Colorado State University}

Melissa D. Reese received a BS in International Business/Finance and an MBA in Management/Organizational Development from Rochester Institute of Technology in 1998 and 2006, respectively. She is currently the department manager of Electrical and Computer Engineering at Colorado State University. 


\title{
Mastering the Core Competencies of Electrical Engineering through Knowledge Integration
}

\author{
Department of Electrical \& Computer Engineering \\ Colorado State University
}

\section{Introduction}

The discipline of electrical and computer engineering (ECE) is a diverse and a challenging discipline for many undergraduate students majoring in this important technical field. With the increasing adoption of information technology (IT) in every aspect of our society and a variety of green energy initiatives, promoting more young people to engage in electrical and computer engineering and to master the core competencies of this important technical field is essential to maintain the competitiveness of the US economy. This endeavor has become a national priority ${ }^{1}$. However, the ECE enrollment and attrition trends in recent years are sources for concern. Enrollment in U.S. institutions of higher education has grown steadily at all levels rising from 14.5 million students in 1994 to 20.7 million in 2009, but such a growth is not fully reflected in science and engineering. Institutions of higher education in the United States granted engineering degrees in the mid-2000s at a lower rate than in the mid-1980s. The number of American students earning bachelor's degrees increased by $16 \%$ over the past 10 years, however, the number of bachelor's degrees earned in engineering decreased by $15 \%$. Nationally, less than $50 \%$ of the students who enrolled in engineering curriculum complete the program ${ }^{2}$. At our university, we typically lose $40 \%$ of our electrical and computer engineering students during the first two years of their undergraduate engineering program. The attrition rate continues to trend downward during the 3 rd year of their engineering program. Figure 1 shows a snapshot of the persistence and graduate rates of the ECE undergraduate program at our university for the 20142015 academic year. Graduation rates reflect the number of students who graduated each year as a percentage of the original entering cohort; and the persistence rates reflect the number of students who graduated and/or enrolled each semester as a percentage of the original entering cohort. Even though Figure 1 captures the graduation and persistence rates in the most recent academic year, the trends have been fairly consistent throughout the history of the department.

One can look at a variety of causes for the attrition trend from social support systems available to students, to low self-efficacy due to poor academic performance, to lack of perceived value and career opportunities relative to the amount of effort required to go through the program, to the rigid ECE curriculum structure and the lecture-style learning environment that discourage active and inquiry-based learning ${ }^{2,3,4,5}$.

This paper describes pedagogical innovations in an ECE department designed to help students gain core competencies in electrical engineering more effectively. By recognizing that key concepts in different core competency areas are often applied to solve real-world engineering problems, the new proposed approach tackles one of the fundamental deficiencies in learning by changing the traditional stovepipe-style teaching and learning. The proposed approach breaks the courses in the core competency areas into a set of learning studio modules (LSMs). Each LSM is self-contained and addresses several anchoring concepts and a set of related concepts in a given 
core competency area. By properly aligning LSMs from different core competency areas, a set of knowledge integration (KI) modules are created to provide an opportunity to stitch together a set of anchoring concepts across different core competency areas to illustrate how a set of anchoring concepts can be applied together to solve real-world engineering problems. The purpose of the new KI modules is to make the overall learning more coherent and to provide context of utilization of these anchoring concepts to increase student appreciation and motivation. Therefore, they play the role of knowledge integration.

Persistence and Graduation Rates of the Current ECE Cohort

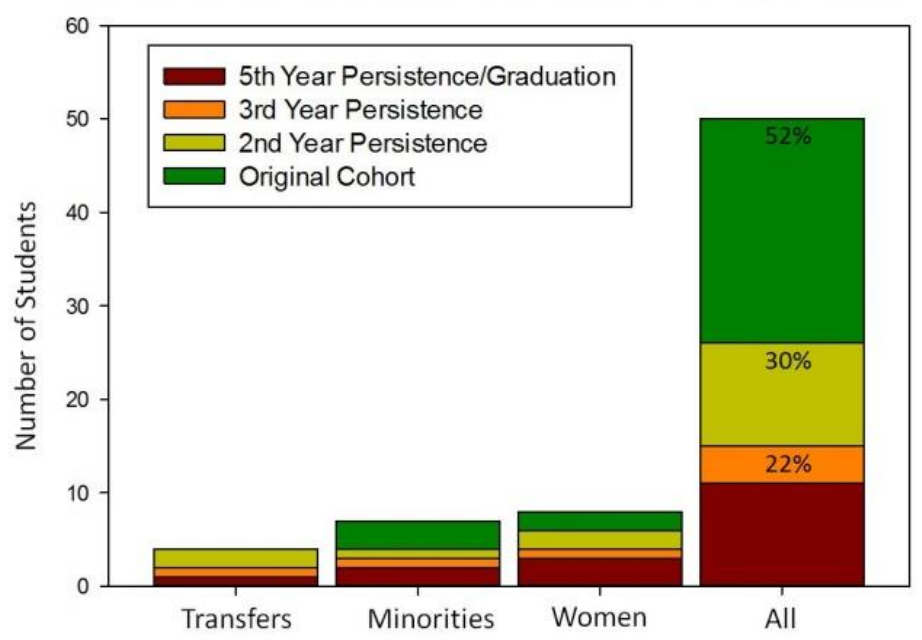

Fig. 1 Persistence and graduation rates of ECE Cohort during the 2014-2015 academic year.

\section{Pedagogical Deficiencies in the Current EE Curriculum}

Figure 2 illustrates the current Electrical Engineering (EE) technical course sequences. Students spend the first two years building the foundation in math, physics, and basic circuit theories both in the digital and analog domains. Courses related to EE core competencies starts from the junior year. The core competencies consist of three pillars: signals and systems, electronics, and electromagnetics. These are three sets of two-course sequences occupying the entire junior year. Table 1 lists the anchoring concepts that are covered by the course sequences in each core competency area during the junior year. The table also lists the accompanying math concepts that are needed to be successful during the junior year of the EE program.

With the requirement of knowing a wide range of fundamental math concepts such as complex variables and their representations/manipulations, advanced concepts of integrations and differentiations, factorization and other algebraic manipulations, gaining core competencies represents significant technical challenges to students enrolled in our EE undergraduate program in three different ways:

- The amount of contents covered increases significantly over time. Many students find it difficult to grasp the concepts because they are abstract and mathematically intense.

- There is a significant dependence on students' mastering of related math concepts.

- Students do not see the connections between core competency courses and how they fit into the big picture, as well as why the mastery of individual topics matters greatly for solving real-world engineering problems. Thus, they lose confidence and motivation. 
The degree of the difficulties experienced by students is further exacerbated by the current approach to teaching and learning with rigid lecture-style and course-oriented curriculum, where subjects within a core competency are taught in stovepipe-style isolation. This approach fails students and society in two critically important ways. First, students with the desire and capacity to become productive engineers are not seeing the relevance of their interests to current curricula, and they are abandoning the discipline. This is especially true for students entering the middle two years of the core undergraduate program where an accelerated amount of new concepts are introduced. Such an isolated learning environment contributes to perceived low utility and value by students. Second, students who ultimately graduate from undergraduate engineering programs may not fully understand the role of an engineer and the scope of the field, resulting in high attrition from employment in engineering, particularly among women.

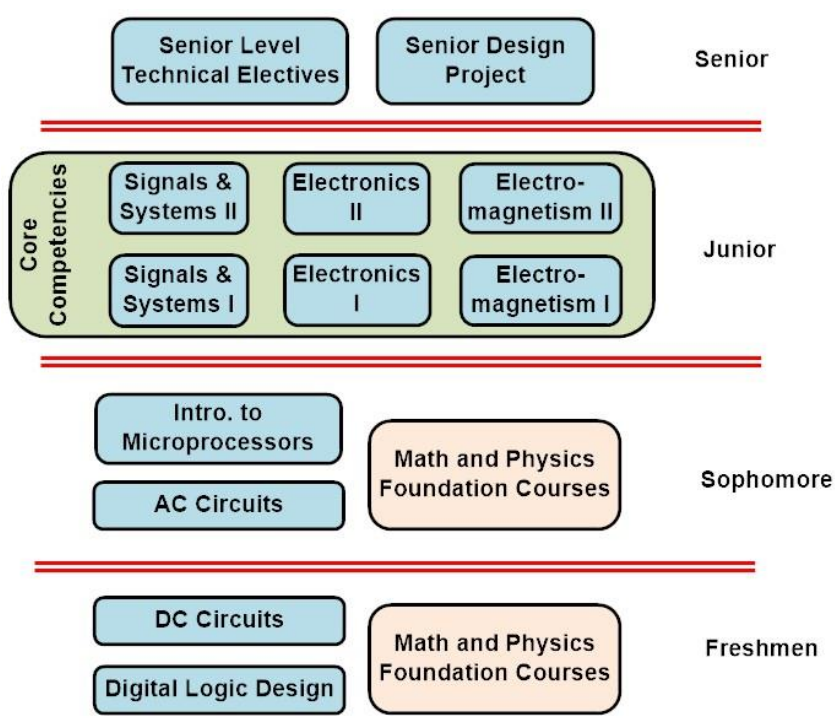

Fig.2. Technical content of the current EE curriculum

Table 1. Anchoring concepts in each core competency

\begin{tabular}{|c|c|c|}
\hline Core Competency & Key Concepts \\
\hline Electronic Circuits & $\begin{array}{c}\text { Transistors, switches, current \& voltage sources, amplifiers, drivers, characteristics of two-port } \\
\text { networks, distortion, gain, frequency analysis, poles and zeros, bandwidth, feedback, stability, and } \\
\text { noise }\end{array}$ \\
\hline Signals \& Systems & $\begin{array}{c}\text { Linearity, time-invariance, causality, stability, convolution, Fourier series \& transforms, frequency } \\
\text { response, bandwidth, energy/power spectral density, sampling, Laplace/Z transforms, filtering and } \\
\text { modulation }\end{array}$ \\
\hline Electromagnetics & $\begin{array}{c}\text { Electric \& magnetic fields, Maxwell's equations, boundary conditions, energy, power conservation, } \\
\text { plane waves, theory of time-harmonic waves, electromagnetic material properties, attenuations, } \\
\text { incident and reflect waves, transmission lines and their circuit models, antenna and radiation }\end{array}$ \\
\hline Mathematics & $\begin{array}{c}\text { Ordinary differential equations, complex variables, series expansions, polar/spherical coordinates, } \\
\text { Green's and Stoke's theorems, and surface integrals, random variables and their distribution } \\
\text { characteristics, }\end{array}$ \\
\hline
\end{tabular}

The current approach of segmenting these concepts into courses taught by different faculty members leaves it up to the students to make the necessary connections among different key concepts in the areas of core competency. This pedagogical deficiency is partially responsible for the lack of perceived utility of the subjects, resulting in lack of interests, lower test scores, and 
ultimately lower self-efficacy. Previous attempts to address undergraduate engineering education have not addressed the barriers caused by the pedagogical deficiency, because they have been largely course-based efforts. Successful first year course reforms range from a one-credit, voluntary introduction to engineering course at the University of Florida ${ }^{6}$ to fully integrated firstyear block curricula, such as Drexel's $E^{4}$ program $^{7}$, the IMPULSE program at MassachusettsDartmouth $^{8}$, the Engage program at Tennessee ${ }^{9}$, and the NSF-sponsored Engineering Education Coalition program ${ }^{10}$. Many ECE programs have adopted separate courses/modules that include more hands-on and project experiences for freshmen to enhance the learning experience. While these efforts have been successful at improving first year retention rates, they have not significantly addressed the long-term graduation rates or attrition from the engineering profession.

\section{Breaking Stovepipes and Interweaving Anchoring Concepts Through Knowledge Integration}

Pedagogically, students' lack of perceived utility and low self-efficacy can be attributed to the lack of threads throughout the curriculum that weave foundational concepts and the creativity and professional aspects of engineering throughout the curriculum. This is particularly true for the sophomores and juniors that are asked to comprehend complex subjects such as electronics, signals and systems, and electromagnetics, in isolation. Knowledge integration (KI) across different core competency areas will become an essential piece in the curriculum to weave together anchoring concepts from different subject contents to make learning more relevant and to improve efficacy. Traditional courses are broken down into self-contained learning studio modules (LSMs) to facilitate KI at key junctures in the junior year of our ECE undergraduate program. Replacing the existing stovepiping structure, the matrix structure is adopted to treat the undergraduate engineering education as a complex system consisting of latitudinal subject content threads and longitudinal integration threads. The concept of knowledge integration is well grounded in cognitively based learning models and the expected outcome of improved selfefficacy and expectancy-value is well documented. The current EE curriculum will be transformed from the structure shown in Figure 2 to a matrix structure shown in Figure 3, where specific latitudinal threads are created to allow progression of learning anchoring concepts in each core competency area. At the same time, specific longitudinal threads are created to interweave latitudinal threads for knowledge integration.

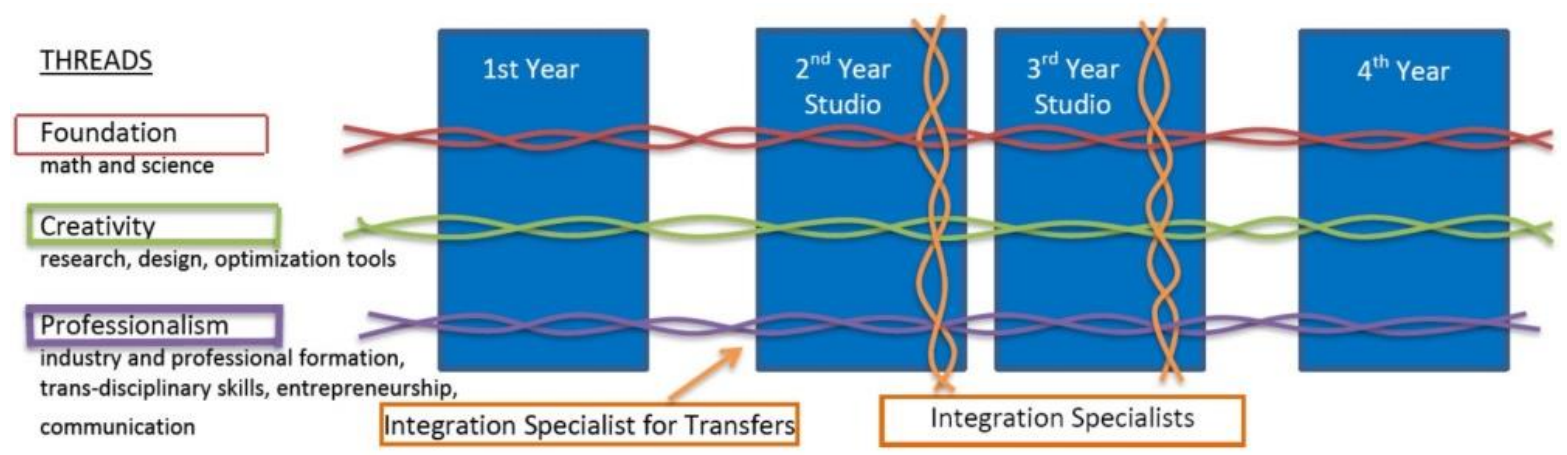

Fig. 3. New matrix-style EE curriculum 
KI modules reinforce the fact that concepts in different core competency areas are highly connected and dependent on each other to make a complex system function as intended. They allow students to gain deeper understanding of the roles the anchoring concepts in each core competency area play through applications. KI modules also provide a platform for better unpacking of math, physics, and engineering concepts to create knowledge coherency among the core competency areas.

To achieve the goals of connecting the "dots" and unpacking anchoring concepts, KI modules use design examples students are familiar with and easy to understand. For example, certain design examples in modern radio systems, such as cellphones, are the ultimate embodiment of a large amount of anchoring concepts in ECE. As students converge to KI modules over time, they will observe how the anchoring concepts they are learning are implemented and applied to a complex piece of ubiquitous technology and its system engineering. Table 2 gives one possible example of three KI modules and the titles of the corresponding LSMs from three core competency areas that serve the KI modules during the second half of the EE junior year curriculum. Since the LSMs in the three core competency areas follow a similar sequence of existing courses in these areas to cover the anchoring concepts, but better aligned time-wise to serve the KI modules, we will focus in our discussions in this paper on KI modules and their relationship with the LSMs in the Table.

Table 2. Examples of LSMs and KIs for the second half of EE junior year

\begin{tabular}{|c|c|c|c|}
\hline Signals \& Systems & Electronics & Electromagnetics & KIs \\
\hline $\begin{array}{l}\text { Complex-freq. spectrum } \\
\text { analysis of continuous-time } \\
\text { signals \& systems }\end{array}$ & $\begin{array}{l}\text { CMOS single- } \\
\text { transistor circuits }\end{array}$ & $\begin{array}{l}\text { High-frequency } \\
\text { electromagnetic } \\
\text { fields }\end{array}$ & \\
\hline \multirow[t]{2}{*}{$\begin{array}{l}\text { Spectrum analysis of discrete- } \\
\text { time signals \& systems }\end{array}$} & $\begin{array}{l}\text { CMOS output } \\
\text { stage driver design }\end{array}$ & $\begin{array}{l}\text { Electromagnetic } \\
\text { waves }\end{array}$ & \\
\hline & & & $\begin{array}{l}\text { Signal analysis of linear and } \\
\text { non-linear circuits }\end{array}$ \\
\hline Filtering \& modulation & $\begin{array}{l}\text { CMOS OTA and } \\
\text { opamp design }\end{array}$ & $\begin{array}{l}\text { Wave reflection } \\
\text { and transmission }\end{array}$ & \\
\hline \multirow[t]{2}{*}{$\begin{array}{l}\text { Computing for spectrum } \\
\text { analysis }\end{array}$} & $\begin{array}{l}\text { Circuit frequency } \\
\text { response }\end{array}$ & $\begin{array}{l}\text { Transmission lines } \\
\text { and waveguides }\end{array}$ & \\
\hline & & & $\begin{array}{l}\text { Practical design of filters and } \\
\text { their applications in modern } \\
\text { radio systems }\end{array}$ \\
\hline \multirow[t]{3}{*}{ Noise } & $\begin{array}{l}\text { Feedback and } \\
\text { stability }\end{array}$ & $\begin{array}{l}\text { Circuit analysis of } \\
\text { transmission lines }\end{array}$ & \\
\hline & $\begin{array}{l}\text { Noise and noise } \\
\text { analysis }\end{array}$ & & \\
\hline & & & $\begin{array}{l}\text { Overview of a complete radio } \\
\text { system }\end{array}$ \\
\hline
\end{tabular}




\subsection{The First KI Module: Signal Analysis of Linear and Non-linear Circuits}

The first KI module looks at the overall analysis of signals from both the time domain and frequency domain to gain better understanding of basic parameters of interest in electrical signals. This is a very important area where it has traditionally been taught alone in Signals \& Systems without the context of circuits that generate or receive signals in question. The goal of this KI is to provide a more complete picture of signal channels to demonstrate effects circuits and their operating conditions have on signals and their parameters of interest. The KI incorporates the anchoring concepts from three core competency areas by using CMOS amplifier circuits and I/O driver circuits with small signal inputs as well as large signal inputs and varying load conditions as a platform. While students learning electronic circuits tend to look at signals in the time domain, a better understanding of circuit behaviors under varying inputs and load conditions, such as linearity under small input signals and output distortion under large input signals and varying load conditions, can be obtained by using what they learned about the frequency-domain analysis techniques in Signals \& Systems and Electromagnetics. Analysis of circuit nonlinearity can be used to gain more insight as to why some design parameters of CMOS circuits, such as biasing and output signal swing, are important to consider when designing amplifier and I/O circuits. In addition, the output from I/O driver circuits can be affected by their load whether they are more resistive (speakers) or less resistive (antenna and transmission lines). The concept of impedance matching and maximum power transfer provides students with a more holistic picture of electronic systems while connecting the anchoring concepts they learned from the LSMs in all three core competency areas. Figure 4 illustrates a schematic of how different components for the KI are connected. The yellow area is the domain covered by Signals \& Systems; the blue area is the domain covered by Electronics; and the red area, including the type of load itself and the transmission media between the circuit and the load, is the domain covered by Electromagnetics. Table 3 list the anchoring concepts the first KI attempts to connect and reinforce.

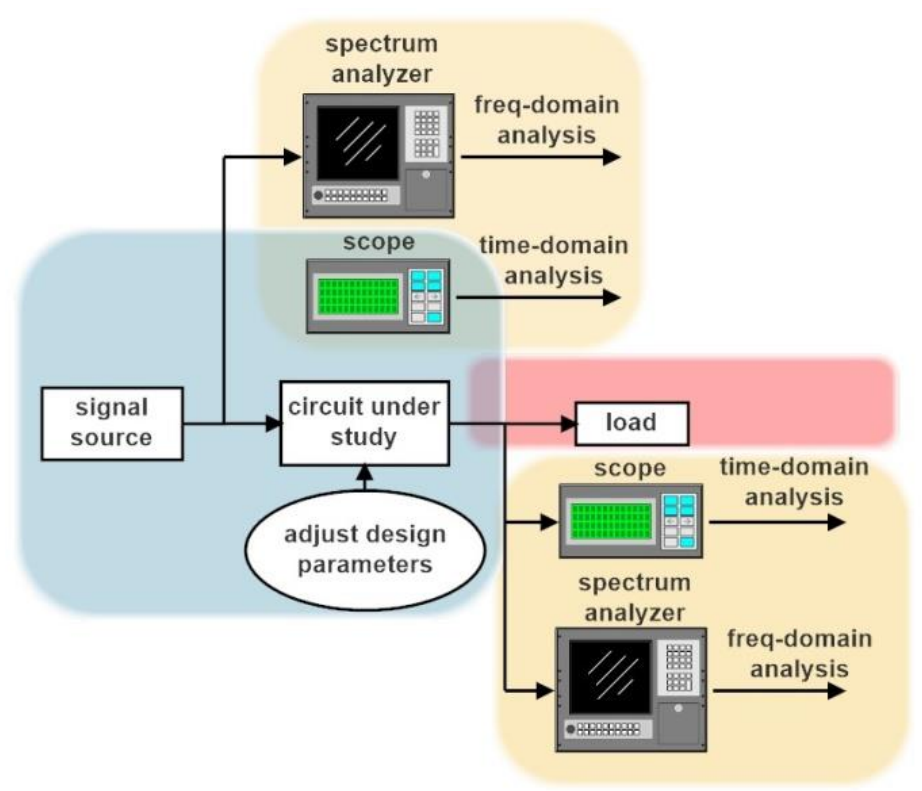

Fig. 4. First KI on signal analysis of linear and nonlinear circuits 
Table 3. Anchoring concepts the first KI attempts to connect and reinforce

\begin{tabular}{|c|c|}
\hline Core Competency & Key Concepts \\
\hline Electronic Circuits & Transistors, current \& voltage sources, amplifiers, drivers, characteristics of two-port networks, \\
distortion, gain
\end{tabular}

\subsection{The Second KI Module: Practical Design of Filters and Their Applications in Modern Radio Systems}

The second KI module examines the design of active filters and their use in radio systems. At this juncture, students have learned opamp circuits and their frequency responses in the Electronics LSMs, filtering and modulation functions and techniques in the Signals \& Systems LSMs, and signal transmission and reflection in different media in the Electromagnetics LSMs. However, filtering and modulation functions are taught assuming ideal opamp functional blocks. The use of real opamp circuits with their non-idealities in filter designs provides a holistic view of one of the most important building blocks in modern electronic systems. With limited gain, bandwidth, and output slew rate, students learn how opamp circuit's parameters impact the overall filter's parameters. For example, with the required filter gain and pass band frequency, opamp's gain-bandwidth product (GBW) must be significantly higher (100X) than the maximum pass band signal frequency. Otherwise, the output of the filter will be distorted. Similarly, limited slow rate of opamps can also introduce additional signal distortion in filter designs. Students will also get to look at the roles of filtering in modern radio systems from the image rejection (bandpass) filters at the frontend, to low-pass filters and anti-aliasing filters at the backend, to matching filters used for impedance matching with antenna or other load components. Therefore, the goal of this $\mathrm{KI}$ is to interweave through many anchoring concepts in all three core competency areas to provide a more holistic view on how these important concepts are applied in a single system. The use of radio system as a demonstration platform is important for three reasons: 1) students are familiar with the platform to start with, saving instruction time to introduce the platform, 2) students' familiarity of the platform makes it easier for student to understand deeper inner workings of the system, and 3) student's familiarity of the platform has a positive effect on student's enthusiasm and self-efficacy. An additional benefit of using a radio system as our platform is that we can include modulation into the discussions during this KI.

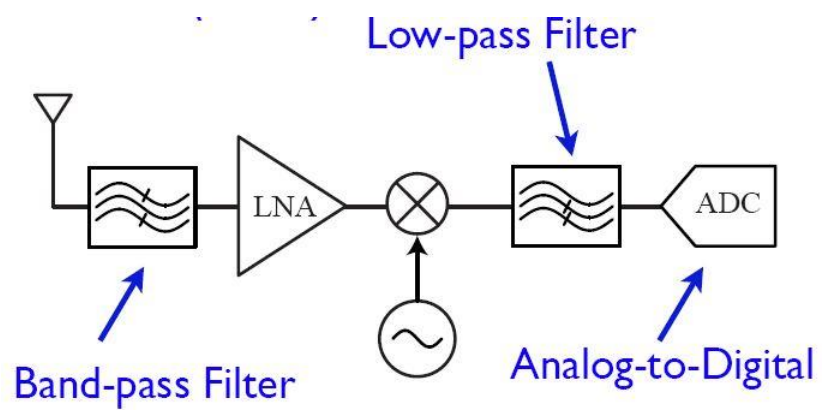

Fig. 5. A simplified view of a radio receiver 
The ultimate embodiment of the modern radio system is modern cell phone. Due to the fact that modern cellphone systems now operate in high frequencies (in the GHz range), the use of SAWtype filters for their excellent characteristics at the high frequency range is preferred in practice. However, the overall cellphone architecture operates using the same principle of heterodyne/homodyne radio as other radio communication systems operating at a much lower ISM frequency band where opamp-based filters play an important role. Students can use cellphone systems conceptually to understand modern radio, but hands-on demonstrations and labs will be for lower baseband applications. Figure 5 shows a simplified view of a radio receiver. Four essential components in the receiver are relevant to this KI. They are the front-end band-pass filter, the low-noise gain stage amplifier (LNA), mixer used as a demodulator, and the low-pass filter at the back-end. Even though students may not be familiar with the details of the analog-to-digital converter, its basic function can be easily explained conceptually in the KI to complete the whole receiver system without affecting the overall goals of the KI.

To complete the second KI module, we add the application of passive filter circuits as impedance matching networks between signal source and load as shown in Figure 6. This technique is often used in radio transmitter designs with the load being an antenna. Students are expected to apply anchoring concepts learned from all core competency areas to understand the need for impedance matching, output impedance of drivers/amplifiers, and design of the matching networks. Table 4 list the anchoring concepts the second KI attempts to connect and reinforce.

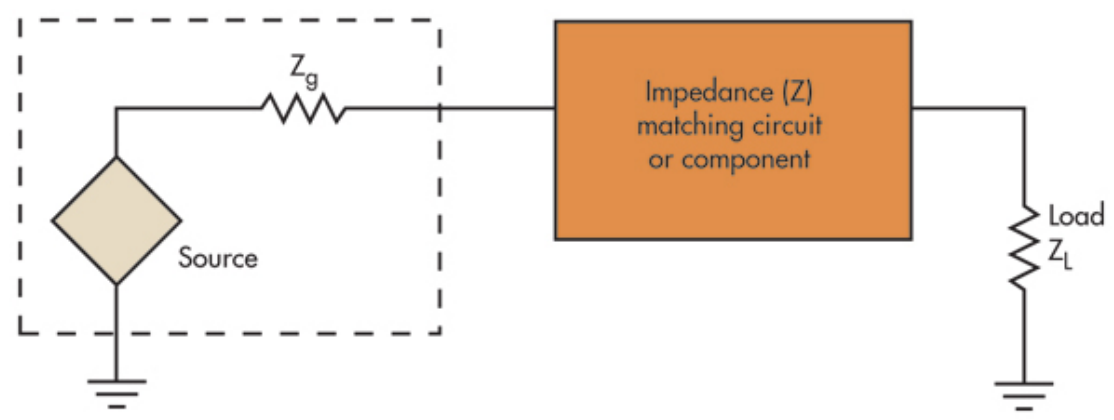

Fig. 6. Passive filter circuit used as an impedance match network between the source and the load

Table 4. Anchoring concepts the second KI attempts to connect and reinforce

\begin{tabular}{|c|c|c|}
\hline Core Competency & Key Concepts \\
\hline Electronic Circuits & $\begin{array}{c}\text { Transistors, switches, current \& voltage sources, amplifiers, drivers, characteristics of two-port } \\
\text { networks, distortion, gain, frequency analysis, poles and zeros, bandwidth, feedback, stability }\end{array}$ \\
\hline Signals \& Systems & $\begin{array}{c}\text { Linearity, time-invariance, causality, stability, convolution, Fourier series \& transforms, frequency } \\
\text { response, bandwidth, energy/power spectral density, sampling, Laplace/Z transforms, filtering and } \\
\text { modulation }\end{array}$ \\
\hline Electromagnetics & $\begin{array}{c}\text { Electric \& magnetic fields, Maxwell's equations, boundary conditions, energy, power conservation, } \\
\text { plane waves, theory of time-harmonic waves, electromagnetic material properties, attenuations, } \\
\text { incident and reflect waves, antenna and radiation }\end{array}$ \\
\hline
\end{tabular}

\subsection{The Third KI Module: Overview of a Complete Radio System}

The third KI module builds on the second KI by including noise into electronic system design. Noise and its associated features are essential in the working of electronic systems. Noise can come internally from the components used in an electronic system in the form of thermal and 
flicker noise. It can also come externally from system's operating environment in the form of interference such as EMI. The goals of this KI is to illustrate to students how noise impacts the overall system operation and to allow students to understand certain design tradeoffs at the system level when noise is considered in the design.

Continuing from the second KI module, students already have a fundamental understanding of both the transmitter and receiver architectures associated with what has been covered by the LSMs in all three core competency areas. This KI will start with radio receiver sensitivity incorporating the concept of noise into the system to illustrate that weak signals cannot be processed if the noise magnitude added by the receiver system is larger than that of the received signal. Given their understanding of the noise from circuit components and their noise bandwidth (from Electronics core competency), students will see a system-level treatment of noise to meet signal-to-noise ratio requirements (from Signals \& Systems core competency) under the constraints of the electromagnetic spectrum allocation for a given application (from Electromagnetics core competency). For example, Figure 6 shows the increased noise level as signals traverse through the receiver from its antenna to the digital converter. The only noise sources considered here are noise generated internally by circuit components in the receiver. Students in this KI module will look at some methods they learned in the LSMs to improve signal-to-noise ratio $(\mathrm{S} / \mathrm{N})$ and to understand ramifications of different options may have. For example, one may look at the option of increasing receiver's input signal power by increasing transmitter's output power, or increasing receiver's input signal power by increasing and redesign transmitter or receiver antenna (physical size)

Band-pass Filter

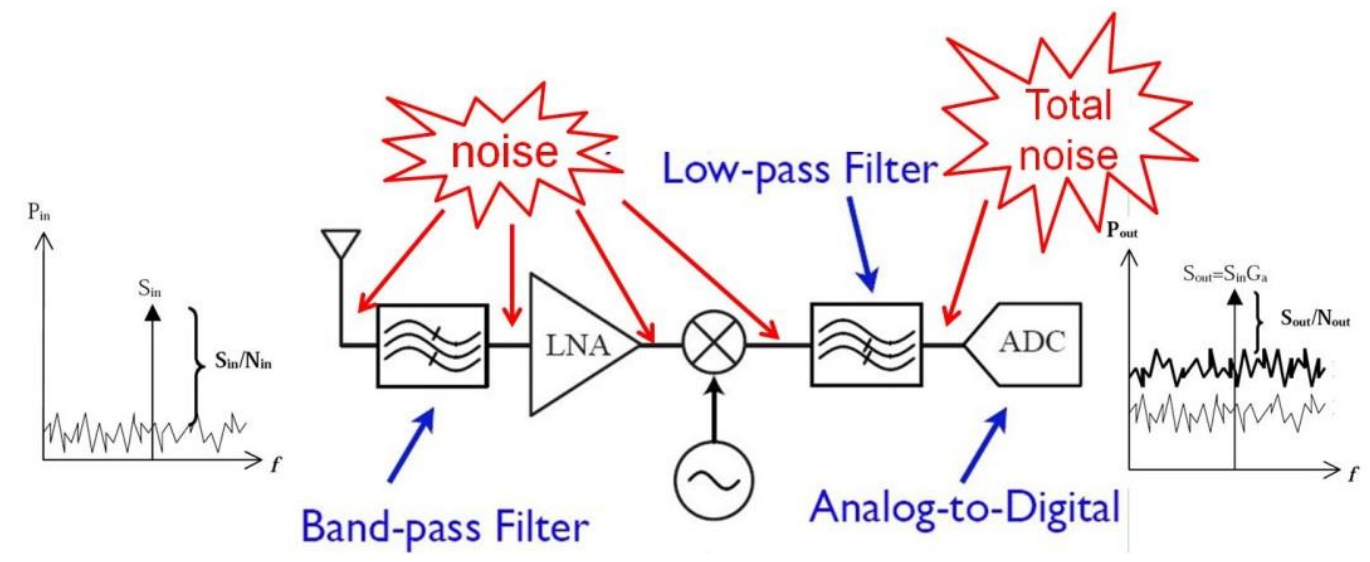

Fig. 6. Noise sources in a simplified radio receiver system

Although both of these two options will be explored to a certain extent in this KI module, especially the option of changing antenna characteristics which is taught in the electromagnetics LSMs, they are ultimately limited by cost, government regulations on spectrum allocation, and consumers' desire for smaller form factors. Alternatively, students are asked to explore receiver component characteristics and how they may change the total output noise. For example,

- how the gain stage (LNA) in the receiver can be changed to lower its noise contribution and what impact these changes have on other gain stage parameters such as gain, bandwidth, power consumption, etc.

- how the filter characteristics (for both the band-pass filter and the low-pass filter), such as the sharpness of cutoff, affect the overall noise level of the receiver, and how to improve the 
sharpness of cutoff of the filters to lower their noise contributions. What impact these changes have on other filter parameters such as cost and power consumption, etc.

These design explorations are invaluable to students as they put what they learned in LSMs from the core competency areas together in the context of a practical system which they are reasonably familiar with. These design explorations are not possible to be done within LSMs.

\section{Discussions}

This paper presents new pedagogical approach to address the attrition trend in undergraduate ECE engineering program. The proposed approach provides both the longitudinal and latitudinal integrations to significantly alter the existing learning model by systematically infusing applications of the anchoring concepts in three core competency areas of the undergraduate ECE program into the otherwise difficult learning process to improve students' appreciation and confidence. The proposed learning model with knowledge integration recognizes the fact that students learn abstract concepts better in the context of a set of familiar applications. The pedagogical paradigm of this approach requires a series of LSMs that focus on individual subject learning intercepted by a series of KI modules as the flow of information moves forward over time. The traditional stovepiping approach shields students from seeing the marvel of engineering design and from connecting how most of the abstract and seemingly "boring" subjects they are learning are actually applied to the magical engineering devices they use on a daily basis.

While this paper proposed some details of several KI modules suitable for the second half of the EE junior year undergraduate program, special attention is needed to balance between depth and breadth of the subjects taught in the KI modules. The KI modules are intended to provide a forum (typically one week long) for students taking LSMs to understand a proper context of the anchoring concepts they are learning to reinforce their learning of these concepts. It is not intended for in-depth discussions related to more advanced technology and method. These will be discussed in their senior electives. Therefore, proper screening and simplification of subjects chosen for the KI modules is required. However, the KI modules do provide a preview of advanced technologies and may serve as catalysts for promoting students interests and desire to stay and finish the ECE undergraduate degree.

\section{Acknowledgement}

The authors acknowledge financial support from National Science Foundation grant EEC1519438. Any opinions expressed in this paper are those of the authors and are not those of the National Science Foundation.

\section{References:}

[1] N. Raisman, "The Cost of College Attrition at Four-Year Colleges and Universities." February (2013): Http://www.educationalpolicy.org. The Educational Policy Institute, Feb. 2013. Web. Nov. 2014

[2] "STEM Attrition: College Students' Paths Into and Out of STEM Field, Statistical Analysis Report." U.S. Department of Education report, NCES 2014-00, 2014. 
[3] Peter A. Daempfle, "An Analysis of the High Attrition Rates Among First Year College Science, Math, and Engineering Majors." Journal of College Student Retention: Research, Theory and Practice 5.1 (2003): 37-52.

[4] Lizzie Y. Santiago and Robin A.M. Hensel, "Engineering Attrition and University Retention." ASEE Annual Conference, San Antonio, TX, June 10-13, 2012.

[5] C. Adelman, "Women and Men of the Engineering Path: A Model for Analyses of Undergraduate Career." National Institute on Postsecondary Education, Libraries, and Lifelong Learning (ED/OERI): Washington DC. ISBN 0-16-049551-2

[6] R.L. Porter and H. Fuller, "New "Contact-Based" First Year Engineering Course." Journal of Engineering Education,Vol. 87 (4), pp. 399-404, 1998

[7] Robert G. Quinn, “Drexel's E ${ }^{4}$ Program: A Different Professional Experience for Engineering Students and Faculty”, Journal of Engineering Education,Vol. 82 (4), pp. 196-202, 1993

[8] N.A. Pendergrass, et. al., "Efficient Development and Implementation of an Integrated First Year Engineering Curriculum," Frontiers in Education (FIE) Conference, 1998.

[9] J. Roger Parsons, et. al., "The Engage Program: Implementing and Assessing a New First Year Experience at the University of Tennessee.” Journal of Engineering Education, 91(4), 441-446, 2002.

[10] Froyd, J. E. "The Engineering Education Coalitions Program." Educating the Engineer of 2020: Adapting Engineering Education to the New Century, National Academy of Engineering, Washington, D.C.: National Academies Press, 2005. 